\title{
Fifth Harrison Lecture 1984: the development of a specialty
}

\author{
R D CATTERALL \\ From James Pringle House, Middlesex Hospital, London WI
}

\section{Introduction}

In 1973 the Medical Society for the Study of Venereal Diseases inaugurated the Harrison Lecture to honour the memory of Lawrence Whitaker Harrison, one of the founders of the British service for patients with venereal diseases. There have been four previous lecturers; Mr Ambrose King in 1974, Professor Thomas Turner in 1976, Dr Claud Nicol in 1978, and Dr Richard Willcox in 1982. Naturally I feel honoured to have been asked to join this distinguished group but also inadequate to fill the role of 5th Harrison lecturer and to find suitable words to describe the achievements of this remarkable man.

\section{Colonel Harrison}

Colonel Harrison was the son of a general practitioner and a Lancastrian. He was born in Haslingdon, near Blackburn in 1876 and educated at Manchester Grammar School and the University of Glasgow. Shortly after qualifying as a doctor he joined the Army Medical Services and served in the South African war and later in India. At this stage of his career his principal interest was in pathology. At the outbreak of the first world war in 1914 he joined the British expeditionary force in France and was soon put in charge of a large hospital for patients with venereal diseases at Le Havre. He quickly organised and directed a hospital that was known for its high standards of investigation and treatment, and he established close communication with the French Medical Officer of Health to help contact tracing. In 1916, however, he returned to England to take command of the refurbished Rochester Row Hospital for venereal diseases, which had 300 beds, and to become adviser on venereal diseases to the War Office. In 1917 he was promoted to the rank of brevet colonel and was appointed honorary physician to the King.

Address for reprints: Dr R D Catterall, 61 Durrels House, Warwick Gardens, London W14 8QB

Accepted for publication 3 March 1984
At the end of the war he was invited by the Minister of Health to take up the post of adviser in venereal diseases to the Ministry of Health and, by a special arrangement between St Thomas's Hospital, the London County Council, and the Ministry itself, to take charge of a VD clinic of his own design at St Thomas's Hospital. After a great deal of wrangling and many broken promises a hut was installed in the hospital grounds, which became the famous Hut E for men patients. Women patients were seen in a converted coal cellar. Colonel Harrison carefully designed the interior of $\mathrm{Hut} \mathrm{E}$, and it subsequently became a model on which many clinics were based throughout the country. Its influence can still be felt in the current clinic design guide sponsored by the Department of Health. ${ }^{1}$ Hut $\mathrm{E}$ was far from ideal, however, and it did not survive. It was totally destroyed by a German bomb in 1940 .

Colonel Harrison was a founder member of the Medical Society for the Study of Venereal Diseases. He wrote more than 100 papers for various journals, contributed chapters for several textbooks of medicine, and was himself the author of three well known books. He eventually became a member of the executive committee of the International Union against the Venereal Diseases and Treponematoses and was largely responsible for the establishment of the British Federation against the Venereal Diseases. Events did not always go his way, however, and he had to fight many battles to establish the service that he thought was desirable. Much of the opposition came from his own colleagues at St Thomas's Hospital. Despite his international reputation he was never appointed to the consultant staff committee of the hospital, and he met opposition to his ideas from many unexpected quarters. He appears to have been a forthright person with great singleness of mind in pursuit of his ideals. His military career left indelible marks on his character, and he was used to giving orders and having them obeyed. The VD service that he founded in Britain had a distinct military flavour, which has persisted in some clinics-for example, in the use of numbers to identify patients rather than their names, the hierarchical structure of the staff, 
and the role of male nurses and orderlies in the clinics.

His great contributions to medicine were recognised by his election to Fellowship of the Royal College of Physicians of Edinburgh in 1925 and his appointment as Companion of the Order of the Bath on the year of his retirement from the Ministry of Health in 1946. From overseas he received the William Freeman Snow Award of the American Social Hygiene Association for distinguished services to humanity. Above all he had won the admiration and respect of his colleagues in Britain and throughout the world, and after his retirement he continued to occupy the role of elder statesman in the subject, to whom many turned for advice and support.

\section{The venereal diseases}

It seems probable that since earliest recorded time men have been aware that certain diseases arose as a result of sexual activity. Details of the types of disease transmitted and the way they were spread were vague and not well defined. There was considerable confusion with leprosy and other infectious skin diseases. Nevertheless it seems clear that in Egyptian, Greek, and Roman times most medical writers believed that there was only one disease of a sexually transmissible nature, which had many clinical manifestations and for which there were various relatively ineffective remedies.

Dogmatic explanations of natural phenomena were challenged for the first time during the Renaissance, but the prevailing view that there was just one disease due to a venereal poison, which had a variety of clinical manifestations and was known as the venereal, was not seriously questioned. Indeed, it received strong support from Paracelsus, and did not come under attack even during the pandemic of syphilis at the end of the fifteenth century. The confusion was further compounded by the personal experiments of John Hunter in the eighteenth century and his complete misinterpretation of the facts. And so the misunderstanding continued until the beginning of the last century when, in 1838 , Philip Ricord provided convincing proof that gonorrhoea and syphilis were separate diseases. Ricord was a Frenchman born in Baltimore who made major contributions to our understanding of disease. It was he who divided the natural history of syphilis into primary, secondary, and tertiary stages. By the end of the nineteenth century three venereal diseases were generally recognised, namely syphilis, gonorrhoea, and chancroid. Some countries later added lymphogranuloma venereum to the list, but little was known about it and the diagnosis was made infrequently.

\section{Medical specialisation}

In earlier days a patient with venereal disease might be treated by a physician, by an apothecary if his disease took the form of a skin rash or other medical manifestations, or by a surgeon if his symptoms were those of urethral discharge or urological complications of infection. The main treatment for venereal disease was with mercury, and some degree of specialisation occurred among the physicians and apothecaries in the use of this highly toxic remedy. Some specialisation also developed among the surgeons who treated such complications as epididymitis, stricture of the urethra, or periurethral abscesses. In published reports much more attention was given to the treatment of men and little to infections in women.

Real medical and surgical specialisation did not begin until the middle of the nineteenth century and arose from new and improved methods of diagnosis and treatment, which resulted from the development of the physical sciences. Medicine gradually became a discipline based on the newer discoveries and techniques of science, and specialised hospitals and institutes began to develop in large cities and universities. Patients attended these hospitals because of the publicity they received and because the results of treatment were often better than in non-specialised clinics and wards.

As a result of the frequent and dramatic skin manifestations of syphilis, especially in the secondary stage, its diagnosis and treatment was gradually taken over by the dermatologists and the specialty of dermatovenereology began to evolve. Towards the end of the nineteenth century and early in the twentieth century syphilis was regarded as a disease within the emerging specialty of dermatology, and many physicians adopted the title of dermatovenereologist and syphilologist. Syphilis was the major interest because of its varied cutaneous manifestations, its toll on health, and because of its economic costs. Gonorrhoea was generally not regarded as a disease worthy of the attention of dermatovenereologists, and was mostly left to surgeons as complications were common after treatment. Strictures of the urethra and abscesses were frequent sequelae, and their management was surgical. The diagnosis and treatment of the few cases of chancroid tended to be undertaken by dermatologists, but little was known about the disease during the early decades of this century.

\section{Dermatovenereology}

Dermatovenereology, or more accurately dermatology and syphilography, attracted some of the most pro- 
gressive doctors and the best minds in medicine in an age when attitudes towards sexual activity for men were liberal and there was no shortage of patients with dramatic manifestations and florid physical signs of disease. It coincided with one of the great descriptive epochs of medicine when new diseases, new syndromes, and new physical signs were being described constantly. Such well known names as Fournier and Brocq in France, Unna and Jadasohn in Germany, Hebra and Neumann in Austria, Morrow and Duhring in the United States of America, and Hutchinson and Morris in the United Kingdom belong to an era of descriptive dermatology and medicine unparalleled in history.

The association of syphilis with dermatology was strengthened by the absence of curative treatment and the fact that mercury, in one form or another, had been found to have a beneficial effect on many of the manifestations of the disease. Mercury was also the great standby in the treatment of skin diseases, and the dermatologists were well versed in its use. Treatment with mercury by inunction, fumigation, or by mouth had serious complications, and cure was uncertain. As the specialty of dermatology developed and expanded, however, it was natural that patients with the most common manifestations of syphilis, namely cutaneous and mucous membrane lesions, should come within the province of dermatology. More specialists therefore adopted the title dermatovenereologist or, in France, dermatosyphilograph. In 1899, however, Fournier stated that in his opinion venereology alone was a specialty as much as any other, and that it took 10 years to train a specialist. He abhorred the fact that medical students could qualify knowing little or nothing about venereal diseases. He pointed out that there was a wealth of teaching material in the hospitals and among the outpatients, and tried to improve the general level of teaching of venereology.

The reputation of the department of dermatology at the Saint Louis Hospital in Paris attracted dermatovenereologists from all over the world to study as postgraduate students. One of these was John James Pringle (1855-1922) who had an extraordinary command of the French language, which he attributed to nightly attendances at the Comédie Française for six months while he attended the clinics of Vidal and Fournier during the day.

In a three year period at the beginning of the twentieth century the study of syphilis was put on a scientific basis for the first time as the result of brilliant research work carried out in Berlin. In 1905 Fritz Schaudinn and Erik Hoffmann discovered the causative organism of the disease by disclosing Treponema pallidum under the dark ground microscope. The next year August von Wassermann, using the phenomenon of complement fixation, described a blood test for the diagnosis of the disease; and then, in 1907, Paul Ehrlich introduced the first specific treatment for syphilis in the form of arsenic.

Meanwhile, there had been progress in the diagnosis, treatment, and management of patients with gonorrhoea. The causative organism of the disease had been discovered in 1879 by Albert Neisser in Breslau (now called Wrochlaw), Poland. This discovery enabled two types of genital inflammatory disease, gonococcal and non-gonococcal, to be identified. The classification of urethritis into these two simple groups, however, was not even accepted widely by 1943 when, at a meeting of the Medical Society for the Study of Venereal Diseases, there was general agreement that practically without exception all cases of urethritis in men were gonococcal. This conclusion is even more peculiar when it is remembered that Ernst von Bumm had first grown the gonococcus on artificial media in 1885, and reliable cultures for Neisseria gonorrhoeae had been introduced by McLeod in Leeds in 1928 .

During the period between the two world wars, 1918 to 1939 , patients with syphilis were most likely to have been seen and treated by a general practitioner or a dermatovenereologist and to have received treatment with one of a variety of treatment schedules consisting of courses of arsenical products given intravenously alternating with courses of bismuth given intramuscularly. New treatment schedules were constantly being introduced as treatment took a long time, side effects were numerous, default frequent, and cure often uncertain. Just before and during the second world war a series of rapid treatment centres was opened in the United States of America, and a variety of shortened courses of improved antisyphilitic products were administered. At the end of the second world war, however, Earle Moore, one of the most eminent syphililogists, stated that despite a great amount of research and years of study, it had to be admitted that there was no general agreement as to which treatment regimen was best for syphilis.

Nevertheless, because of the complexity of treatment with arsenic and bismuth and the frequent and serious side effects, some of which could be fatal, a group of specialist therapists developed to whom physicians and surgeons frequently referred their patients for antisyphilitic treatment. In this way a minor specialty, based uniquely on a technique of treatment, developed. Such specialties are rare in medicine and, apart from radiotherapy and the chemotherapy of malignant disease, tend to be short lived. The specialists in treatment with heavy metals and the rapid treatment centres lasted only about 30 years before radical changes in treatment rendered them obsolete. 


\section{Chemotherapy and gonorrhoea}

Towards the end of this period a dramatic change occurred in the treatment of gonorrhoea, the other major venereal disease. Until the late 1930s gonorrhoea in men had been treated principally by the use of urethral irrigations with a variety of antiseptic solutions, such as potassium permanganate and oxycyanide of mercury. The pressure in the irrigation can and tube tended to push any infected material higher into the genitourinary tract, and complications such as epididymitis, acute prostatitis, and abscesses of Cowper's and Littrés glands were common. Strictures of the urethra were frequently the result of prolonged infection and inappropriate treatment. They were treated by dilatation with sounds of various sorts, and special dilators were devised, such as Kolman's dilator and Oberländer's sound, which earned a terrible reputation with patients as instruments of torture and as a means of retribution for sins.

In 1937, however, the introduction of the sulphonamides for the treatment of microbial infections revolutionised the treatment of gonorrhoea. It suddenly became possible to treat patients who had the disease with a handful of tablets taken by mouth, and in the early days there was a remarkably high cure rate. The irrigation cubicles and the douche cans became obsolete and the special treatment centres were no longer essential. The surgeons, urologists, and venereologists who had been largely responsible for these treatments turned their attention elsewhere, and for a few years the treatment of gonorrhoea was a relatively simple matter of microbiological diagnosis and oral chemotherapy with sulphonamides or, more often, empirical treatment with sulphonamides alone by general practitioners.

The treatment of women with gonorrhoea and other types of genital inflammatory disease was largely undertaken by gynaecologists and was very unsatisfactory. Complications were common, and pelvic inflammatory disease was difficult to treat. Tracing the sexual partners of men with the disease was not widely practised, and when the International Union against the Venereal Diseases and Treponematoses tried in 1938 to persuade governments to encourage contact tracing, the suggestion was met with strong opposition and hostility. This was typified by the statement of a leading Belgian dermatovenereologist who said that contact tracing was not part of the traditions of Belgian medicine and was not to be recommended.

So at the beginning of the second world war in 1939 the management of patients with the venereal diseases, syphilis and gonorrhoea, was fragmented and undertaken by general practitioners, private doctors and specialists in several different disciplines. Early infectious syphilis in men was treated by dermatovenereologists as a small part of their work with skin diseases or at public clinics. Late syphilis of the cardiovascular system was treated by the cardiologists, and neurosyphilis by the neurologists. Gonorrhoea in men was treated mostly by general practitioners, urologists, at the public clinics, or by private doctors. Much less interest was shown in venereal diseases in women, who might be seen by a general practitioner, at a public clinic, or by a gynaecologist. Unfortunately there was usually no communication between the doctor treating the man and the doctor treating the woman. Venereology was very fragmented and showed little or no tendency towards cohesion.

\section{The effects of penicillin}

In 1929 Sir Alexander Fleming discovered penicillin, which was to revolutionise the treatment and prognosis of many bacterial diseases. It took 15 years before a satisfactory preparation became available for the treatment of human disease and, as everyone knows, Mahoney, Arnold, and Harris first demonstrated its efficacy in the treatment of early syphilis in 1943 in New York. This discovery was to have widespread and undreamt of consequences, and its initial effects on venerelogists, dermatovenereologists, syphilographers, and all those interested in syphilis and gonorrhoea was revolutionary. Syphilis, which had previously been a difficult disease to treat and required long complex treatment schedules, could now be cured by a short course of injections lasting only a few days, and patients were rendered noninfectious within a matter of hours of starting treatment. ${ }^{2}$ Gonorrhoea was easily cured by a single injection of penicillin, which was timely as the gonococcus was just beginning to develop serious resistance to the sulphonamides.

The treatment of the two important venereal diseases became so simple that it removed the necessity for special treatment centres and special venereal disease clinics, and they soon started to close. Diagnosis and treatment moved out of the municipal and teaching hospital clinics into the hands of general practitioners and the private consulting rooms of private doctors, especially in the United States but also in Europe. As the number of new cases at the public clinics fell, local and national funds declined, there was little basic research, and almost no epidemiological activity. Venereology was in sharp decline. Earle Moore, that great perfectionist in diagnosis and treatment and the most influential man in the world on syphilis, wrote that venereology was dying and venereologists should 
move into other specialties. He likened the postwar venereologist to a fighter pilot whose aeroplane had been shot to pieces around him and who was parachuting to earth. The pilot had only a little time during his descent to think about which other specialty he would like to adopt, and the message that venereology was doomed came over loud and clear. Earle Moore converted his prestigious syphilis clinic at the Johns Hopkins Hospital, universally known as Medicine One, into a clinic for chronic diseases, and in 1954 he discontinued the publication of the American Journal of Syphilis, Gonorrhea and Venereal Diseases after only 39 volumes had been published, and converted it into the Journal of Chronic Diseases. Everywhere interest in venereal diseases declined and clinics were closed.

Some people doubted the wisdom of Moore's precipitous actions and questioned whether control of the diseases would be maintained. The most outspoken of these was Ambrose King, who questioned the truth of the concept that venereal diseases were declining. ${ }^{3}$ He pointed out that after a decade of decrease in incidence there was good epidemiological evidence that the incidence of gonorrhoea and syphilis were again increasing and that the tide had turned. By the early 1960 s there was strong evidence of a widespread and massive return of these infections throughout the world, which coincided with the introduction of safe and effective oral contraceptive pills and a new outlook on sexual activity.

\section{Changing attitudes to sex}

The new radical changes in attitudes to sexual activity were most apparent in North America and Western Europe during the 1960s and 'seventies. Because of earlier sexual maturity young people were having sexual experiences at a younger age, and during those decades premarital sexual relationships for both girls and boys became part of normal behaviour in the West. Changes of partners and casual sexual activity were easier and safer as a result of the widespread use of contraceptive pills. The pill had the effect of dissociating sexual activity from procreation for the first time in human history, and fear of pregnancy was completely banished making total sexual freedom safe from this point of view. As a result, people's expectations of sexual activity took on new dimensions, and an active satisfying sex life began to be regarded as a human right that should be available to all.

At the same time people became less inhibited when discussing sexual matters, and pamphlets, books, the cinema, radio and television, and above all the theatre became much more explicit about sexual matters. As a result people became more imaginative and more daring in what they did sexually, and orogenital, anorectal, and other forms of sexual expression became more widespread, making detection of sexually transmitted infections more difficult.

During this era repressive laws and regulations about homosexuality were repealed in many countries, and a more liberal and tolerant attitude towards homosexual activity became fashionable. Homosexual patients began to feel that they could go to doctors and clinics and confide their problems without fear of embarrassing the doctors or being met with judgemental attitudes. It soon became apparent that there was a very high incidence of infection among homosexual men, and repeated infections with sexually transmitted agents were common in this group.

\section{Resistance to antibiotics}

The antibiotic era had started promisingly with penicillin, but problems gradually became apparent. Even the sulphonamides had only been fully effective against $N$ gonorrhoeae for about six years before some strains of the organism developed resistance and made the drugs relatively ineffective in treating gonorrhoea. Fortunately penicillin became available towards the end of the second world war to fill the gap, and for the next 30 years the treatment of gonorrhoea and syphilis was simple and effective. Nevertheless, over the years it was observed that certain strains of $N$ gonorrhoeae were less sensitive than average to penicillin, although clinical cure could always be obtained by increasing the dose. It was therefore a cause of great anxiety when the World Health Organisation drew attention to the fact that $\beta$-lactamase producing strains of $N$ gonorrhoeae were being reported with increasing frequency from a growing number of countries. ${ }^{4}$ These strains were not only being spread by air travellers from areas where they were common, such as West Africa and South East Asia, but they became endemic in several countries in Europe, such as Holland and the United Kingdom. The recognition of strains insensitive to penicillin, spectinomycin, kanamycin, and the cephalosporins heralded the arrival of the gonococcus resistant to many antibiotics and all the problems that it entails. There is, however, still no evidence that the treponeme causing syphilis has become less sensitive to penicillin over the years.

Many other factors have been responsible for the increase in the prevalence of venereal diseases, including the massive immigration of workers from underdeveloped countries to work in the expanding industries of Western Europe and North America. The continuing high levels of infections stimulated a 
growing interest in them and particularly a strong research activity using methods and techniques not available in the past. As a result, a great deal of new knowledge became available not only about the venereal diseases themselves but also about a whole range of other infections that were previously unknown or not thought to be sexually transmitted.

\section{The newer sexually transmitted diseases}

Increasing expectations of bodily function, comfort, and hygiene among the general population, greater willingness and enthusiasm to take part in research projects, and the application of new and previously untried techniques of investigations have yielded a multitude of previously unidentified microorganisms in patients with genital inflammatory disease. Agents such as Chlamydia trachomatis, Gardnerella vaginalis, Ureaplasma urealyticum, and Mycoplasma hominis have all been shown to occur frequently and usually to be sexually transmitted. Indeed $C$ trachomatis has now been established às the most common genital pathogen in many areas of the world. Viral diseases due to herpes simplex virus, hepatitis B virus, cytomegalovirus, the human papillomavirus, and several others are all now recognised as being predominantly sexually transmitted. Overall there is general agreement that there are about 26-28 infectious agents spread by sexual contact in addition to the three classic venereal diseases, which now constitute less than $16 \%$ of all the cases of infection diagnosed at the clinics.

The constantly changing pattern of human disease is well illustrated by the sudden appearance in early 1981 of the acquired immune deficiency syndrome (AIDS), which is causing grave anxiety among sexually active people, especially homosexual men. Deaths of young men from opportunistic infections and from Kaposi's sarcoma are increasing and, although it is not fully established that AIDS is caused by an infectious agent that is transmitted sexually, the epidemiological evidence points strongly in that direction.

\section{The new specialty}

The great increase in the number of diseases known to be transmitted sexually and the growing volume of patients seeking advice about them led, during the 1960s, to dissatisfaction with the name venereal diseases for this group of infections and, even more, with the term venereologist for the specialists in diagnosis and treatment. It was felt that the older term venereal disease, or VD, had both emotional and judgemental overtones, was associated in the minds of the public with sexual guilt, and was inappropriate in the modern climate of sexual freedom and tolerance. In any case it now only applied to less than 1 in 6 of the patients attending the clinics.

Gradually the term sexually transmitted diseases, or STD, became more widely used, especially in the United Kingdom and later in other English speaking countries. This term was adopted and used at most international and national meetings and has been the standard terminology at the World Health Organisation for more than a decade. It was the general view that this name, while describing clearly how the diseases were spread and grouping them together satisfactorily, did not produce the personal embarrassment or evoke the guilt feelings associated with the name VD or venereal diseases. It was rapidly adopted by doctors, nurses and journalists, and above all by the patients themselves.

As these changes in attitudes and terminology were taking place, diagnostic and research methods were becoming even more sophisticated and scientific. Microbiologists began to provide diagnostic services for a wide range of organisms including $C$ trachomatis, $G$ vaginalis, and $U$ urealyticum and to investigate the incidence of $\beta$-lactamase producing strains of $N$ gonorrhoeae. At the same time virologists turned their attention more and more to diagnostic and research aspects of genital herpes, hepatitis B, and cytomegalovirus. The successful development of a vaccine against hepatitis B gave great encouragement to workers in the subject, and the scientific basis on which the study of the sexually transmitted diseases resided was greatly strengthened.

The improved service to patients at clinics, and the liberal and understanding attitudes of the staff, resulted in a noticeable increase in the number of patients attending the clinics seeking advice from doctors about a wide variety of sexual matters in addition to sexually transmitted diseases. Sexual counselling and help with a large number of problems related to sexual activity form an increasing part of the work at the clinics. The details of clinical practice in the 1980s are completely different from those prevailing when the venereal disease clinics were first established, with their concentration on syphilis and gonorrhoea.

Patients with the classic venereal diseases, the first and second generation of sexually transmitted diseases, sexual and psychosexual problems, and other medical and surgical conditions, patients requesting a check up, and those suffering from guilt and remorse all attend clinics and doctors in increasing numbers. Demand for a new type of medical care has developed during the past two decades and most health services are not able to deal satisfactorily with it. The difficulty is to persuade 
health authorities to provide the facilities as well as the trained doctors, nurses, and back up staff to deal with the growing number of patients.

The emergence of the sexually transmitted diseases as an area of medical specialisation in certain countries has resulted from the work and enthusiasm of a small number of dominant figures in centres where facilities for a clinical service and research have been available. It is now widely acknowledged that the demand for such a specialty exists all over the world, but everywhere there is at present a shortage of interested properly trained doctors and nurses, and facilities are usually inadequate and overcrowded so that waiting rooms are choked with patients. Doctors can therefore devote only a very limited amount of time to each patient, despite the complexity of the medical, behavioural, and personal problems with which they present.

\section{Other types of services}

In most countries throughout the world the service offered to the public is still provided by departments of dermatovenereology. In this way the historical connection between dermatology and the skin manifestations of syphilis has continued into the new era of sexually transmitted disease. In the European Economic Community eight of the 10 member states have combined departments, and in only two of them have the disciplines been separated. Dermtovenereology is practised almost exclusively in Latin America, South East Asia, parts of Africa, the socialist republics of Eastern Europe, Russia, and the Middle East.

In the United States of America and Canada a service is provided by the public health authorities and state and provincial health departments in the form of clinics in the large urban areas. The Venereal Disease Control Division of the Centre for Disease Control (CDC) in Atlanta is responsible for providing grants, training, and technical assistance as well as fostering research. About $80 \%$ of patients with sexually transmitted diseases, however, are believed to see private doctors who have usually received little or no training in the subject. Although strong in research, the United States of America is very underdeveloped clinically, and standards of practice in this specialty are frequently unsatisfactory.

In university centres in certain developing countries in Africa the doctors who provide the microbiological service for the hospitals and the region rotate through the clinics and gain experience in caring for patients and in diagnosis and treatment. Many of them are sent to Britain to work for diplomas in both microbiology and sexually trans- mitted diseases before returning to Africa to start new laboratories and clinics or to work in already established centres.

\section{The British system}

A completely different system has grown up in the United Kingdom based on the recognised medical specialty of venereology, more recently called sexually transmitted diseases and now increasingly known as genitourinary medicine. As a result of legislation passed by Parliament in 1916, a chain of clinics was established in large hospitals throughout the country, many of them based on the famous model clinic established by Colonel Harrison at St Thomas's Hospital. When a fully comprehensive National Health Service was introduced in Britain in 1948 the clinics were taken over and became an integral part of the service. This was a most favourable development because the specialty became estâblished on equal status with the other medical and surgical specialties, and consultants working in the subject were given equal privileges and undertook the same responsibilities as their colleagues in other fields. The British service for patients with sexually transmitted diseases has now been in existence for over 66 years and has been adapted to meet rapidly changing circumstances. It started as a typical VD service and is now developing into a sophisticated, wide-ranging, scientifically based medical specialty providing a clinical service in keeping with the needs and wishes of the patients. ${ }^{5}$

\section{Separate specialties}

In recent years it has been pointed out that, since the decline in the number of new cases of secondary syphilis, the association of dermatology and sexually transmitted diseases as a single specialty is no longer satisfactory. The two subjects have grown steadily apart, with dermatology moving closer to internal medicine and sexually transmitted diseases being more influenced by microbiology. The training and skills required for the practice of dermatology do not combine well with those required for the management of patients with sexually transmitted diseases. This difficulty is illustrated by the well known fact that the more senior and experienced members of a department of dermatovenereology find it difficult to maintain their interest in sexually transmitted diseases and frequently leave this work to the junior members of their staff, who are often without adequate training, supervision, or guidance.

Few, if any, of the major advances in our understanding of the sexually transmitted diseases in recent years have come from combined departments of 
dermatovenereology. Most of these departments practise fragmented aspects of the specialty only. The statistics from most combined clinics show that most patients diagnosed as having sexually transmitted disease are men, and comparatively few women patients are seen for investigation. Of these only a minority are found to be infected. Responsibility for diagnosis and treatment, and especially for contact tracing and surveillance, is generally uncertain, and this aspect of the work tends to be very unsatisfactory.

A growing number of doctors working in the discipline are convinced that the two subjects have become so widely separated that their practice together at modern specialist standards is no longer possible or desirable. Those who have given up one side of the combined specialty, whether it be dermatology or venereology, are usually very satisfied with the change, which enables them to concentrate their efforts on one or other of the two growing specialties. It was cutaneous syphilis that brought the two specialities together over a century ago and now it is the decline in incidence of these manifestations which makes their eventual separation seem inevitable.

The type of patient attending clinics in most countries has altered radically during the past 25 years due to social, economic, and cultural changes. They are better educated, more vociferous, and expect more thorough investigations and more detailed information from their doctors than in the past. Unfortunately the existing structure and organisation of medical care results in fragmentation of the services so that it is still quite uncommon for a husband and wife or a boy and his girlfriends, let alone a group of homosexual men, to be seen by the same doctor.

\section{The name of the new specialty}

One of the important outstanding problems is the name of the new specialty and of the doctors who practise it. The older names such as venereology, dermatovenereology, or syphilology are too narrow and now no longer accurate or appropriate for the developing specialty. The term sexually transmitted diseases has important limitations, although it is and has been a useful descriptive term during a period of transition.

In modern medicine most of the other major specialties, such as cardiology, gastroenterology, or neurology, have names related to organs. It has been suggested that the new specialty should be brought into line with other medical disciplines and adopt such a name. Most of the patients coming under the care of doctors in the new specialty will have disease presenting with genitourinary symptoms and signs. It has therefore been proposed that the name genitour- inary medicine might be suitable for the subject, $\stackrel{\frac{\Phi}{\triangle}}{\frac{D}{2}}$ department of genitourinary medicine for the depart- 므 ment, and genitourinary physician for the doctor practicing the specialty. In fact this terminology has $\underset{\overrightarrow{2}}{\vec{*}}$ been adopted recently by over $75 \%$ of all clinics in $\stackrel{?}{-}$ the United Kingdom, and very favourable reports have come from patients, general practitioners, $\frac{\bar{c}}{\bar{\omega}}$ consultants, and other doctors interested in the $\vec{\nabla}$ specialty. There appear to be no problems of $\Omega$ confusion with urologists, and there is general के agreement that the new name makes referral of $\vec{\circ}$ patients by other practitioners much easier for both the patient and the doctor.

What sort of a doctor will practise genitourinary medicine in the future? He or she should be a well trained physician with previous experience in a number of medical specialties and should have a or higher degree or diploma, preferably Membership of $\underset{\omega}{\omega}$ the Royal College of Physicians. Entrance into the specialty, however, should be very flexible and full training in other specialties, such as obstetrics and $\overrightarrow{0}$ gynaecology, plus some experience in general medicine, would probably be acceptable. In addition to National Health Service training posts at registrar $\stackrel{\mathbb{\Phi}}{-}$ and senior registrar level linked with a career $\vec{\bullet}$ structure in the specialty, there should be some $\stackrel{\infty}{\oplus}$ academic posts and a limited number of chairs in genitourinary medicine. High priority should be given to undergraduate and postgraduate teaching, and courses for nurses, laboratory workers, and contact tracers should be encouraged. ${ }^{5}$

\section{Genitourinary medicine}

It is important to stress once again that the proposed change is not just a change in name, but a fundamental change in attitudes and medical practice $\stackrel{0 ?}{=}$ whereby patients with sexually acquired diseases and allied conditions would receive clinical services and attention similar in quality to that provided for $\delta$ patients with other non-sexually acquired diseases. This high quality service would be made available in 은 modern carefully designed outpatient departments $>$ and in general medical wards, totally divorced from the old, secretive, cloak and dagger, special clinics $\bar{N}$ hidden away in some dark corner of the hospital. The of new departments of genitourinary medicine would be $\tilde{N}$ active subspecialties of internal medicine, where both $\underset{\omega}{\mathcal{E}}$ the general medical and specialist standards of patient care, research, and teaching would be among 0

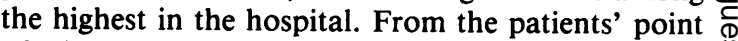
of view the developing specialty of genitourinary $\stackrel{\mathscr{D}}{+}$ medicine offers a broadly based primary health care $T$ service, free of charge to all residents in the United Kingdom, and available at over 200 clinics throughout the country. 
Unfortunately, however, the emergence and development of the new specialty of genitourinary medicine has not always been spearheaded by the medical profession but rather by the patients themselves. Doctors have often been insensitive to the requirements of their patients and have retained their judgemental attitudes towards infected patients. Medical planners and administrators have been blind to the new developments. Even more disappointing is the fact that the deans of most medical schools and others responsible for undergraduate medical teaching have failed to appreciate the implications of the changes in attitudes to sexual activity and the development of the new specialty. As a result undergraduate teaching of the subject is usually inadequate and frequently non-existent.

World wide these changes will probably be slow because in most countries the specialty of dermatovenereology dominates the field and blocks progress. Nevertheless, medicine is in a period of great change and doctors are having to consider the wishes and needs of their patients more and more as the media expose areas of medicine that were rarely discussed in the past. Leadership towards the development of the specialty of genitourinary medicine must come from countries like the United Kingdom where the changes are rapidly being adopted and integrated into the general medical scene.
The detailed form that the new specialty will take and its future development will no doubt be slightly different in each country and region of the world, depending on the cultural, religious, social, economic, and medical backgrounds of the patients and their doctors. Nevertheless, the need and demand are apparent and, as their expectations increase, the patients are becoming more vociferous. The concept of genitourinary medicine as a broadly based, scientifically orientated, medical specialty is the natural development of a subject which began as venereology, later became dermatovenereology, evolved through sexually transmitted diseases, and is now emerging as a specialty suitable to the needs of sexually active people in the 1980 s.

\section{References}

1. Department of Health and Social Security. Special treatment clinic: a design guide. London: HMSO, 1974.

2. Moore JE. Penicillin in syphilis. Oxford: Blackwell Scientific Publications, 1947.

3. King AJ. These dying diseases-venereology in decline? Lancet 1958; ii: $651-7$.

4. World Health Organisation. Neisseria gonorrhoeae producing penicillinase. WHO Weekly Epidemiological Record 1976;51: 293-4.

5. Catterall RD. The British service for patients with sexually transmitted diseases. Health Trends 1983;15:82-5. 